\title{
Educational Consciousness: Breaking Open the Category of Knowledge in Footscray
}

Charman K, Dixon M, Bellingham R, Thomas M \& Cooper J

Public Pedgagogies Institute

\begin{abstract}
This article is the beginning of a theoretical reading of a project undertaken by the Public Pedagogies Institute a Pop Up School and Educational Consciousness. Drawing on Biesta's notion of publicness we initially describe the Pop Up School event. We argue that in this project we look to extend the way the knowledge profile of an area can be more fully informed by turning to the community itself for their articulations and representations of their knowledge. When then offer distinct readings of this research/public event with Deleuze and Barad as they offer a dynamic engagement with knowledge. The paper then moves between the small space of the public event and the larger space of Footscray through Aboriginal and non-Aboriginal cosmologies and pedagogies. Time is called then into play as a psychoanalytic reading of Footscray, memory and knowledge are read from the interview data. The final steps bring Footscray sharply through time with a reading of 'consumptionscapes' of Footscray knowledge.
\end{abstract}

\section{Keywords}

knowledge, educational consciousness, publicness, public pedagogy 
For most of 2016 researchers at the Public Pedagogies Institute (PPI) have been working on a project a titled 'Pop Up School and Educational Consciousness'. The Institute itself is focused on learning and teaching outside of formal institutions. To this end the Institute has an ongoing interest in and commitment to the recognition of specific geographical knowledge-what a community knows and values as it's significant knowledge. This current major project-Pop Up School and Educational Consciousness-reflects a critical engagement with what constitutes knowledge. We have undertaken an iteration of this project in Footscray, an inner suburb of Melbourne and at the time of writing this article we have just completed a similar project in Werribee an outlying suburb on the fringe of Melbourne. From each of these projects, our intent is to produce a document titled Toward a Footscray Curriculum and Toward a Werribee Curriculum. This curriculum will include knowledge and distinctive processes of learning and teaching that are unique to these localities.

Like the Footscray curriculum, this article is a cacophony of voices reflecting both the knowledge we experienced in our research and the beginnings of our theorisation. This article begins with a discussion of the process of assembling the Pop Up School and some of the ways in which the event itself and research in geographically situated knowledge might be understood.

The determining of knowledge in a specific geographical space necessitated the multiple 'conversations' about valued knowledge, teaching and learning with the people who populate the area. This process of having a 'conversation' is the creation of an atmosphere where, after a few guiding questions, the resident, community group, employee or employer is determining of the conversation. These conversations were recorded and photographs of relevant people, places and objects were taken. During the conversations with the respective groups time is spent discussing ways this knowledge and understandings of learning could be a contribution to the Pop Up School event. The success and quality of this project is dependent on ongoing focused engagement with the community in these 'conversations' in the lead up to the event. The Pop Up School event is a day-long public event with participants and exhibitors from the community showcasing local knowledge, teaching and learning. The possibilities for learning and teaching into the future emerge from these 'conversations' and from the Pop Up School.

In the Pop Up School the notion of 'public' is better thought of as 'publicness'. Gert Biesta (2014) argues for pedagogy in the interest of publicness. He distinguishes this mode from pedagogy for the public that is to educate the public administered by the State, and pedagogy of the public that is done by the public itself. Publicness is a good description of the Pop Up School. As the knowledge that was enacted in the space was, as Biesta writes drawing on Hannah Arendt:

'...concern for the public quality of human togetherness and thus for the possibility of actors and events to become public, or to create a form of political existence... in which action is possible and freedom can appear' (p. 23).

However, the project consisted of not just the Pop Up School event, but also the collection of responses to the question of 'what is knowledge in Footscray?' We wanted to understand knowledge relative to a geographical space and we have tended to think of this knowledge as educational consciousness, as all knowledge that has been learnt and brought to the fore is the collective understanding of what we now know.

This work draws upon the well-established tradition of theorisation and research of historical consciousness (Seixas, 2004; Guttman 1983). The study of historical consciousness differs from the study of History, which is the study of the past, and from historiog- 
raphy, which examines how historians view the past. The study of historical consciousness is the study of how people look at the past. In the same way, the study of educational consciousness differs from the study of education. We were interested in a theorisation of educational consciousness as the study of how people look at education, knowledge, learning and teaching. We began with the idea that educational consciousness refers to individual and collective perspectives and understandings of both institutional and organic or informal education and learning. The theory is not static. It has so far provided us with a means to consider and notice how people see knowledge as emerging from relations between such things as personal and family experience, the body, geography, context, culture, society, and the past, present and future.

The undertaking of a project around educational consciousness is political because it is another approach to the question of 'what is community?' PPI is concerned with learning and teaching that occurs outside of formal institutions, such as schools and universities. There can be a tendency to see the growth of knowledge through a narrow lens of skills measured by state and national schooling measurements such as NAPLAN and PISA results. We argue these are limited indicators. Performance on these national and international testings is linked to individual schools and to geographical location. In Australia, the MySchool website records individual school data on NAPLAN tests alongside ICSEA data. ICSEA stands for the Index of Community Socio-Educational Advantage and this index is used to argue there is a strong relationship between educational advantage, as measured by the parents' occupation and the level of education completed, and their educational achievement (ACARA, 2011). The researchers in this project look to extending the way the knowledge profile of an area can be more fully informed by turning to the community itself for their articulations and representations of their knowledge.

In the body of this article which follows, we represent our engagement with the educational consciousness of Footscray through four independent but interwoven steps. Initially we go to the Pop Up School event itself and addresses the opportunities and the challenges for the researchers in seeking evidence of 'educational consciousness' in a public event far from the constraints of an interview or focussed conversation. Reading this research/ public event with Deleuze and Barad offers a dynamic engagement with knowledge. The paper then moves between the small space of the public event and the larger space of Footscray through Aboriginal and non-Aboriginal cosmologies and pedagogies. Time is called then into play as a psychoanalytic reading of Footscray, memory and knowledge are read from the interview data. The final steps bring Footscray sharply through time with a reading of 'consumptionscapes' of Footscray knowledge. The article concludes with a recognition of the positioning of these knowledge steps inside Footscray's greater educational consciousness.

\section{The Pop Up School as Research Event}

The pop up school is a performance of knowledge. At the pop up school sounds circulate unhooked from the meanings of words. The language of knowledge is dislodged from its sovereign position. Bodies moved through the space-objects were produced, burnt, slashed.

Sound reverberated against the brick walls that enclosed us. Skateboards rocketed up and down the alley way. The square-the site of the pop up school-was an out of the way space in between the back doors of shops frequented by those 'hanging around' the neighbourhood, not far from shops and trains and buses. A place named as 'ready for re-activation' by the council. We were in the space-looking for knowledge. The performance of knowledge was a public one in this space. 


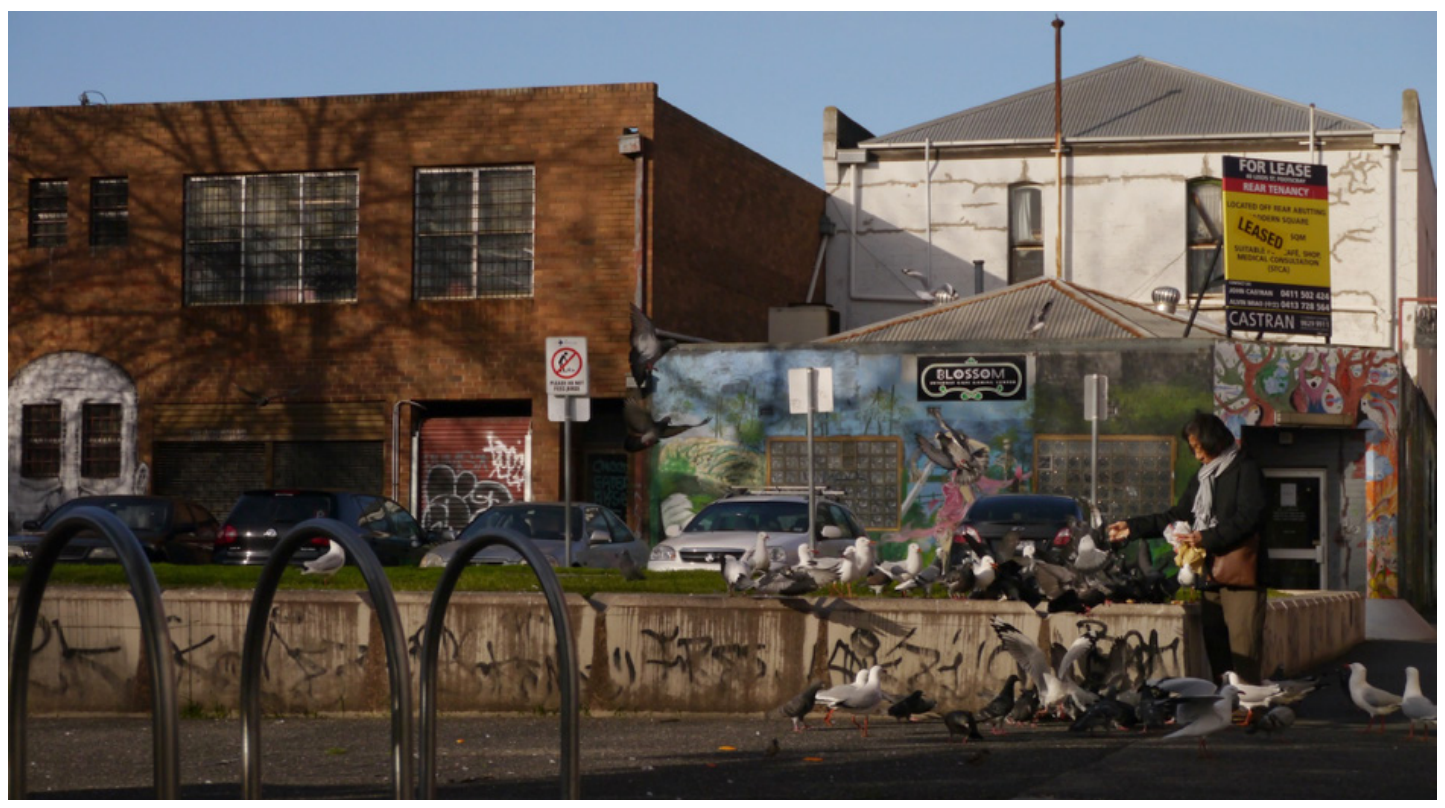

Figure 1: Maddern Square, the site of the Pop Up School (photograph: Jayson Cooper, 2016)

The project asked of us crucial questions. What is the knowledge? What will it look like? How will it be felt or experienced? What are its shapes, contours, bodies? Where should we look for it? In words, in objects, documents, in images? From whom will we seek this knowledge? Once found, how will we hold it, or name it? How do we break open this category of knowledge? If we do so, what will be produced? What does this foreclose? One way of looking is to read through Deleuze (1994) and attend to the becoming and the becoming and the becoming of knowledge. For Deleuze, 'knowledge is irreducible to a static body of facts but constitutes a dynamic process of inquiry as an experimental and practical art embedded in experience' (Semetsky, 2009, p. 443). Knowledge is an experiment with and a performance of the world.

The Pop-Up School is a research cut. Following Barad (2014) the agential cut; an act of cutting things together-apart in one movement, can be understood as an image of time, a diagramming between subject and object, that 'constantly produces itself and grows' (p. 37). Cutting, Barad (2011) contends, is not an activity that simply severs a part from a whole, but engenders a discontinuous passage where something new emerges. The Pop-Up School and this research provide the conditions to make this cut; to both attend to and co-constitute the emerging knowledge with/in these communities.

At the Pop-Up School in Footscray, knowledge mattering was present as a flow of matter: the walls that bounced back the sounds, that roughed the images pasted up by the schools and the scrawling's of poetry from participants. The wall of Maddern Square held the stories of those who hung out that day and sang songs of their identity. Wool held in the hands of the local knitters was entangled with others who joined them, their stories, their dynamic knowledge, the needles, and the sun on their faces. Knowledge was brought to matter in maps and stories; dancers and singers; the fire of the leaves burning for welcome; fire to make message sticks; the drawing on sticks by child and by adult; the smashing of knowledge mattering piñatas of racial stereotypes made by young Vietnamese teenagers. 


\section{Aboriginal and non-Aboriginal Cosmologies and Pedagogies}

Footscray marks and maps the movement of people over time. This southern contact zone is a meeting place where the cultural, social, political, and environmental enmesh and become-with each other through past-present interactions. Public Pedagogies Institute's Pop Up School activated public pedagogy that is in the interest of publicness (Biesta, 2014), working reciprocally with and through Aboriginal and non-Aboriginal cosmologies and pedagogies. We followed an ethic of 'what comes from place, must serve place'. Through the Pop Up School we created a space for Aboriginal and non-Aboriginal ways to meet and interact. Creating message sticks opens alternatives and possibilities to witness the ways we share and teach each other through doing. These interconnected stories are held in this message stick.
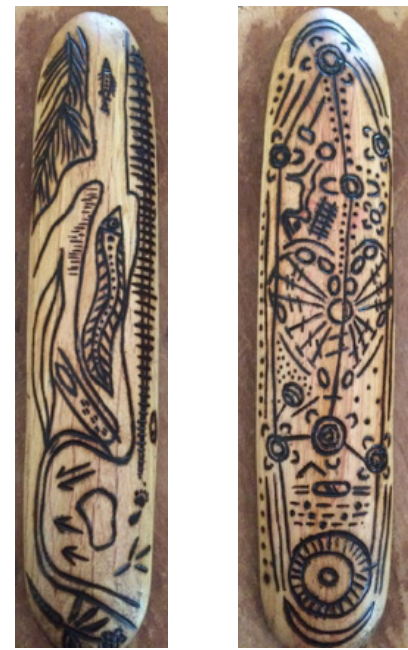

Figure 2: Footscray Pop Up School message stick (carved by Dr. Tyson Kaawoppa Yunkaporta)

A shared construct of public pedagogy is enacted through the connections with, and between, place, objects, matter, ontology, culture, art, and weaves both over, under, and through the intermingling narratives borne from this one-day public event. The Pop Up School project is 'relationship-centric' (Martin, 2016) and through these acknowledgements and introductions we are making visible the relatedness entangled in this project. In doing this there are many human and more-than-human entanglements, all people (human and more than human) that are part of this, came together to generate a one day event; carving cosmologies.

Pratt (1991) introduced the term 'contact zones' to consider when cultures and peoples meet. In this meeting place, she highlights the interactions between peoples as they coalesce, 'clash, and grapple with each other, often in contexts of highly asymmetrical relations of power such as colonialism, slavery, and their aftermaths as they are lived out ... today' (p. 34). Contact zones are dynamic sites of opposition and harmony. Martin Nakata (2007), a Torres Strait man, extends this idea further to consider the interface which arises when two cultures meet. He calls this The Cultural Interface and it provides a theoretical lens for us to consider the approaches we take in teaching and learning with Aboriginal communities, peoples and cultures. To consider the differences and similarities between and across cultures, places and peoples, and to celebrate these differences. This is one of the dangers of terms such as diversity when used in neoliberal contexts; it becomes a unifying agent which strips away difference. 
The Pop Up School became the dynamic meeting place of cultures, knowledges, ways of being and doing. The community, through doing, came together to imagine new possibilities. In effect, an imagined community bound together through an imagined cohesion, where place was imagined by community to generate senses of place and the sharing of this. Through the Pop Up School our public interactions are imagined and articulated as a shared aesthetic. This enables us all to disrupt, interrupt and reject the 'oppositionality which colonialism brings into being' (Ashcroft, Griffiths, \& Tiffin, 1995).

Opposing the colonial spinnerette that has cast its web of European values and ways of being over this southern landscape is an important contribution in thinking about how knowledge is both enacted and understood. Such values have even re-inscribed and reshaped the landscape to suit a European aesthetic. In this process Indigeneity has likewise attempted to be erased. A southern theory (Connell, 2007) rejects the north as the epicentre of knowledge production, and instead looks to the knowledges and ways of doing and being that are unique to these southern places. In our research project Educational Consciousness, and the Pop Up School, we are seeking these southern knowledges, these local identities, and we are celebrating them with the keepers of these stories; this includes migrant stories, historical stories, Aboriginal stories; how we feel connected to places; how we as a group of people made up of many nationalities live and be together. A southern theory (Connell, 2007) speaks of an Australian identity and what that means, and is inclusive of Aboriginality. This intermingling and enmeshing of peoples from around the world takes place on sovereign soil. Footscray always was and always will be on Aboriginal land. In particular the Boonwurrung people of the Kulin Nation.

Through the Pop Up School we enacted a de-colonial contact zone beyond the gates of formal schooling. Pratt when talking about contact zones says:

'We used the term to refer to social and intellectual spaces where groups can constitute themselves as horizontal, sovereign communities with high degrees of trust, shared understandings, temporary protection from the legacies of oppression... groups need places for healing and mutual recognition, safe spaces in which to construct shared understandings, knowledges, claims on the world that they can then bring into the contact zone' (Pratt, 1991, p. 40)

In this way the Pop Up school created pedagogies of healing and mutual recognition that generated safe spaces for a united aesthetic in the heart of Footscray to flourish. In the 'contact zone' of the Footscray Pop Up School the cosmologies of the population were co-constructed together; from the community and by the community. This generates a pedagogy of resistance in the interests of publicness.

\section{A Psychoanalytic Reading of Footscray, Memory and Knowledge}

People often speak of something as occurring in the past to indicate that a sense of continuity has been lost. In the speaking they bring something back, they bring it closer. Memory is often linked to the past. Memory is doubted as unreliable in the face of rationality. However, memories are being made constantly and the work of memory ensures that the past is always present.

One way of thinking about a place over time is as a geographical layering that is both physical and cultural. In such a rendering both geography and culture are intertwined. Collectively we effect the physical geography and this in turn is determined culturally. Marxist geographers read spaces through imperialist and colonial re-shaping of geographies. Competing and sometimes conflicting cultural frameworks determine current urban planning. Significant knowledge in this instance might be heritage, both recent and 
from the more distant past. Some knowledges are silenced in the interest of dominant cultural perspectives. However, silence does not mean absence-when all are forming the space. One way of thinking about the research, about the past undertaken in Educational Consciousness and the Pop Up School project is through psychoanalysis. Julia Kristeva (1992) writes of interpretation:

'The very fact of positioning oneself as an interpreter, regardless of the actual meaning one finds in one's object...is rooted in the subject's need for reassurance as to the stability of his or her identity'.

Kristeva writes, of the Stoic notion of the primordial inter-dependence of interpretation, subjective will, and mastery of time. What a psychoanalytic reading is, and how it departs from mastery, is that it offers an understanding of the inherent instability of the interpretation of the object.

In psychoanalytic theory, there exists a crisis of interpretation and it is inherent in the symbolic function itself. By this we can understand the symbolic is always infused by elements of the imaginary (in the Lacanian sense of the dimension of images conscious or unconscious, perceived or imagined) and that the symbolic is inherently unstable. Speech itself is symbolic but infused by the imaginary. The dimension of desire opens up time as an interpretive power, but also a transformative power which Kristeva calls the imaginary. The realm of the imaginary and interpretive closure produces a perpetual creative force. In Psychoanalysis, there is no absolute meaning — nothing can be reduced to a single meaning.

In the section below there are extracts of interviews with people from the Footscray Historical Society. The idea is to disrupt the tense and in so doing bring the stories told into the present in an effort to render the memory as contemporaneous. In so doing the idea of the past is disrupted where it has become something that is no longer present, instead through this disruption it is brought to the fore and what is created is a sensibility that what is spoken is occurring now. This is how psychoanalysis understands the unconscious. The unconscious is outside of time, so when something is experienced from the unconscious it is as though it is occurring now.

Footscray has is a rich educational history. Schools are were present before the Government system of schooling was is in place. Religions such as the Anglican and Catholic Church provided education. "So, there was is the Catholic school, and the church of England school, Penny schools. They you pay paid a penny, I think, a penny I don't know if it is was a penny a week? or what it is was. And actually, according to John...they are not weren't very good teachers. They built school rooms before they erected churches, and the efforts of clergymen and congregations was are supported by land grants and building subsidies administered by the school board. The list of subscriptions towards the erection of a catholic school in Footscray, reveals many protestant donors. Each school accepted accepts children of any religious persuasion. They had have Catholic and Anglican priests, and lessons took take place after school for those children whose parents wished wish them to attend. That's probably what they should be doing now. [reading from a book] The Church of England school had has the larger attendance, 50 boys and 44 girls, on average in 1861. In 1860, an inspector was is astounded to discover that the school had has neither desks nor forms, organisation was is judged poor, and the standard of instruction weak. Mr Llewelyn does not appear to have any energy. There is not the slightest animation in his manner. His teaching is dull and heavy, and all but slovenly. Unfortunately, you still get teachers like that today. (Interview)

In the experience of the 'past', memory spoken can be understood as rendering what is being re-called present. What has occurred here is still occurring here. 


\section{Consumptionscapes in Footscray's Educational Consciousness}

One way of thinking about educational consciousness is as of 'consumptionscapes' in Footscray. We conceive of 'educational consciousness' as the synthesis of place, time, community and memory of learning and knowledge. Drawing upon Public Pedagogy and Popular Publics, it could be argued that educational consciousness tells us that what is being learnt in Footscray is a form of symbolic consumption. It is learned through identification with Footscray, in which the idea of Footscray has become a gentrified commodity to be purchased. Gentrification (Rofe, 2003) and the consuming culture (Kenway \& Fahey, 2011) are aspects of a larger global movement, with implications for education more broadly.

'Probably 10 years - maybe I mightn't pinpoint it to 10 years, but all the houses that have been knocked down and square, box apartments been put up, the high rises that are going up - whereas before you could look from say, the ... oval and look down and you would never see apartment houses like the Barkley Theatre Apartments and the apartments on the other side of the road a little bit further down towards - what's the street? French Street - is it French Street? The ring road where there's more apartment houses and then the state trustees building right on that-right on the corner in the-and making the-they're built right on the pavements-right on the roads and there's no nicety about them. They're-the architect style is very forbidding-concrete jungles as I call them. They haven't set them back and perhaps did some sort of-on the outside did something that's more tasteful and things get knocked down. There's another apartment house going up in-around the ring road extension of Picket Street where the Chinese temple was. There's another one-but they just seem to not care for the architect of years gone by, really. I mean, where they've put some high rises, I mean they're-that was probably car yards and different things like that, but I mean, you go along and you see-I call it when you've been to the dentist and had a tooth taken out, all of a sudden there's a space and where's the house gone and there've been some nice houses taken down and they're taken down because they're on quite a big block of land and they're going to get 8,10 double story apartments which - it's like a bad tooth. They don't fit into the landscape so they stand out so much' (Interview).

This is the rise of a new Footscray in which a global identity is pushing out a local personality, leaving only specters behind.

Footscray, as rendered, is a community of juxtapositions. 'There's often a remaking of areas like Footscray, thinking that there's no history value' (Interview). There are those who adore the turbulent seas of a suburbs past and have lived through its shady history, and those who are just keen to pick up a cheap sailor's uniform after the event, yet claim that same history as their own. In the wake of sustained uniform change, how much diversity will be sustained by an ongoing global homogeneity which continues to drive sameness across communities?

\section{Footscray's Educational Consciousness}

The four approaches to theorising educational consciousness offered in this paper gesture towards the depth and the breadth of readings of local knowledge which are available when we break open the category of knowledge. The knowledge emerging and valued in this project demonstrates an educational consciousness which is less about transferable and useful skills for employment or success, but more about the meeting of zones of contact and past, present and future, as sites of affordance of possibility. Footscray holds, and continues to construct, deep levels of knowledge of migration, art, culture, identity, 
belonging, history, language, and the body. These are not reducible to lists of facts and expertise but are written into the streets and the lives of its population, they are dynamic and truly diverse, put to work in the daily lives and identities of those who call Footscray home. Written into the streets and used to construct new businesses, new community, new futures and possibilities. This public performance of teaching and learning as seen through the Pop Up School celebrates the everyday and holds this knowledge in the social and cultural fabric of the suburb. It teaches and learns in a multitude of ways. The Footscray Pop Up School and the research project Educational Consciousness capture a moment in time in a vibrant tapestry of knowledge found in Footscray. Weaving the everyday into lives, and living our lives in inclusive and democratic ways that demonstrate the tapestry of life, art, identity and memory.

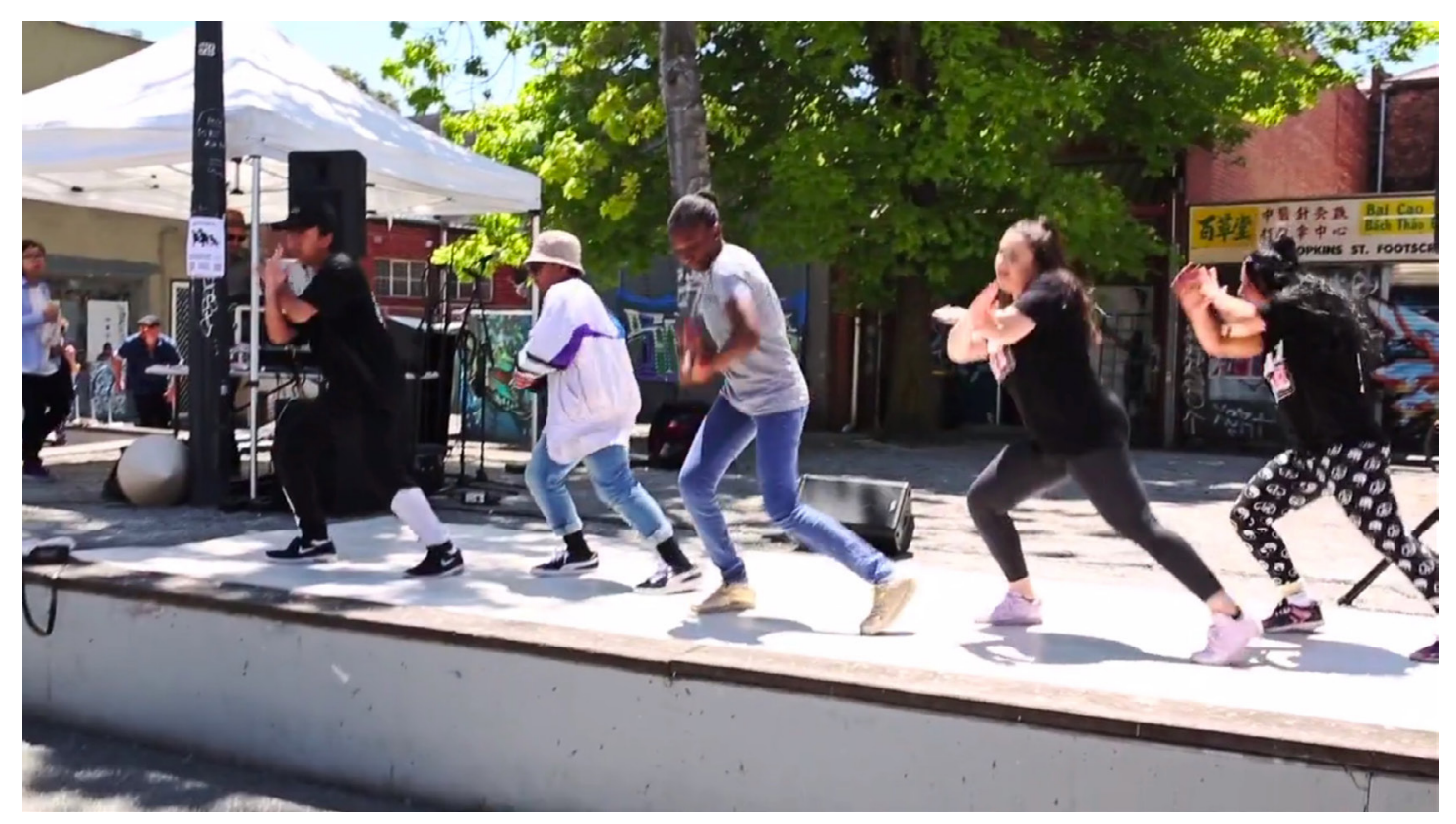

Figure 3: Still from Footscray Pop Up School, 2016, (Click on image above to play video)

\section{Video Link}

Footscray Pop Up School, 2016, https://vimeo.com/241816652

\section{References}

Ashcroft, B, Griffiths, G, \& Tiffin, H 1995, The Post-Colonial Studies Reader, Routledge, New York.

Barad, K 2014, 'Diffracting Diffraction: Cutting Together-Apart', Parallax, 20(3), 168187. doi:10.1080/13534645.2014.927623

Biesta, G 2014, 'Making Pedagogy Public: for the Public, of the Public, or in the Interest of Publisness?' in J Burdick, J. A. Sandlin, \& M. P. O’Malley (Eds.), Problematizing Public Pedagogy (pp. 15-25).

Connell, R 2007, Southern Theory: the Global Dynamics of Knowledge in Social Science, Polity, Cambridge. 
Deleuze, G 1994, Difference and Repetition (P. Patton, Trans.), Columbia University Press, New York.

Guttman, H 1983, Presidential Address, 'Historical Consciousness in Contemporary America', Organisation of American Historians Annual Conference, Cincinnati.

Kenway, J, \& Fahey, J 2011, 'Public Pedagogies and Global Emoscapes', Pedagogies: An International Journal, 6, 167-179. doi:10.1080/1554480x.2011.554626

Kristeva, J 1992, The Kristeva Reader (Ed Toril Moi), Blackwell Publishers, Oxford.

Martin, KL 2016, Voices \& Visions: Aboriginal Early Childhood Education in Australia, Pademelon Press, Baulkham Hills.

Nakata, M 2007, 'The Cultural Interface', Australian Journal of Indigenous Education, 36

Pratt, ML 1991, 'Arts of the Contact Zone', Profession, 33-40.

Rofe, MW 2003, 'I Want to be Global': Theorising the Gentrifying Class as an Emergent Élite Global Community', Urban Studies, Routledge, New York , 40(12), 2511-2526

Seixas, P(ed.) 2004, Theorizing Historical Consciousness Seixas, University of Toronto Press

Semetsky, I 2009, 'Deleuze as a Philosopher of Education: Affective Knowledge/Effective Learning', The European Legacy, 14(4), 443-456. doi:10.1080/10848770902999534 